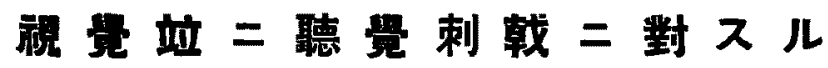 脊髓反射二就 テ
}

\author{
岡山圈科大學生理學教宝 (主任生沼教授)
}

岡田正矩

\begin{abstract}
緒 言

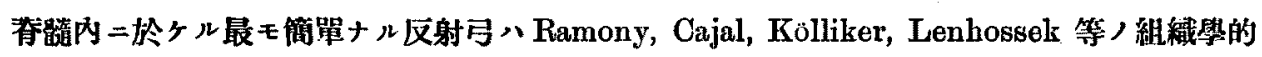

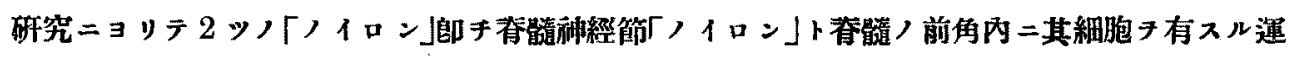

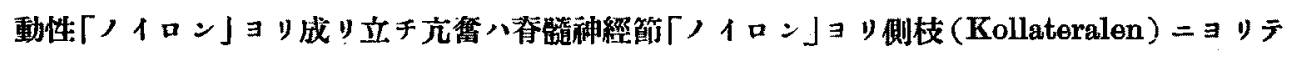
直接荤動性「ノイロン」二達スル事 證明セリ。

其後 Verworn, Baglioni 及ビ Tiedemann 等ハ向ホ此外二春籍神經節「ノイロン」ヨリ來レル

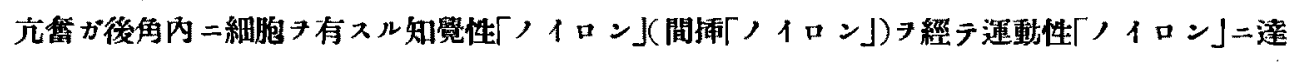

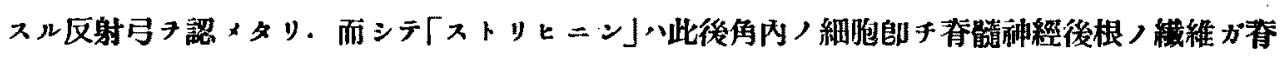

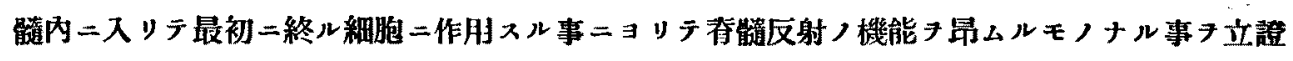
七リ.
\end{abstract}

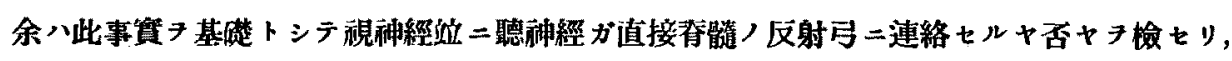
即チモシ直接連絡フリトスレハ「ストリヒニン」中毒ノ蛙い光ノ刺戟又心音波ノ刺戟二ヨリテ反 射强值起スベキナリ。

\section{1. 光覺刺载二對スル脊簿反射}

Verworn 八光営湖戟垖チ光線 云一y.

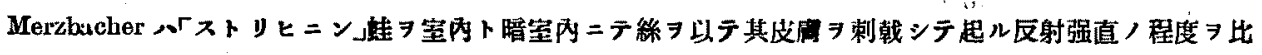

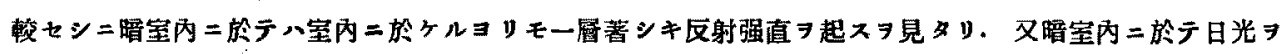

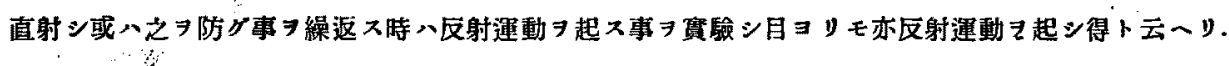

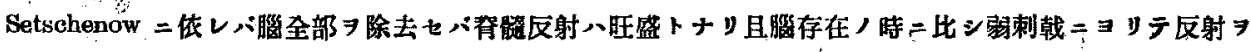

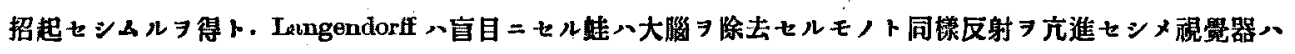
反射 7 抑制スト云一y.

\section{實 驗方 法}

Geinitz 及ビ Winterstein ノ賽驗二依レバ溫度高キ時ハ反射機能 減退セシムルガ故ニナル ベク低温ノ場所タ選ビ晚秋ヨリ初春二於テ實駿フ行ヒタリ。 


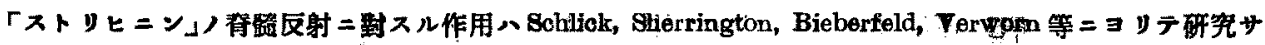
レ Matkiewies, Meihuizen, Eekhard 等=袋レボ 1/60 mg 「「ストリヒニン」ハ殆ド作用ナク 1/50-1/30 mg

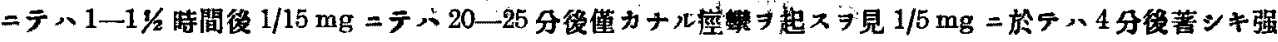

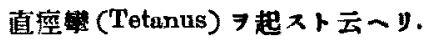

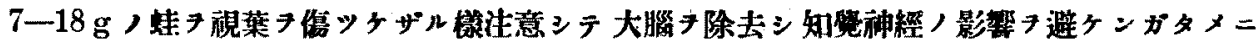

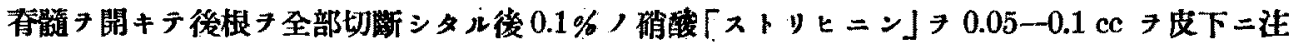

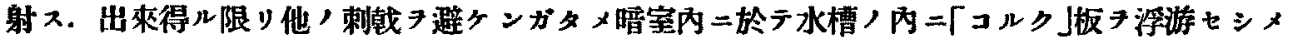

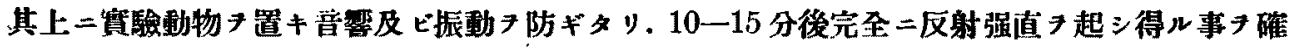

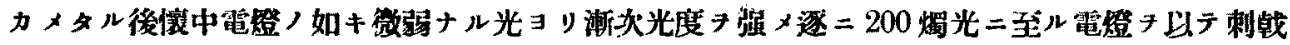
セリ及日光/直射 7 以テ检セリ。

其成績ノ 1 部キ表示スレバ次ノ如シ.

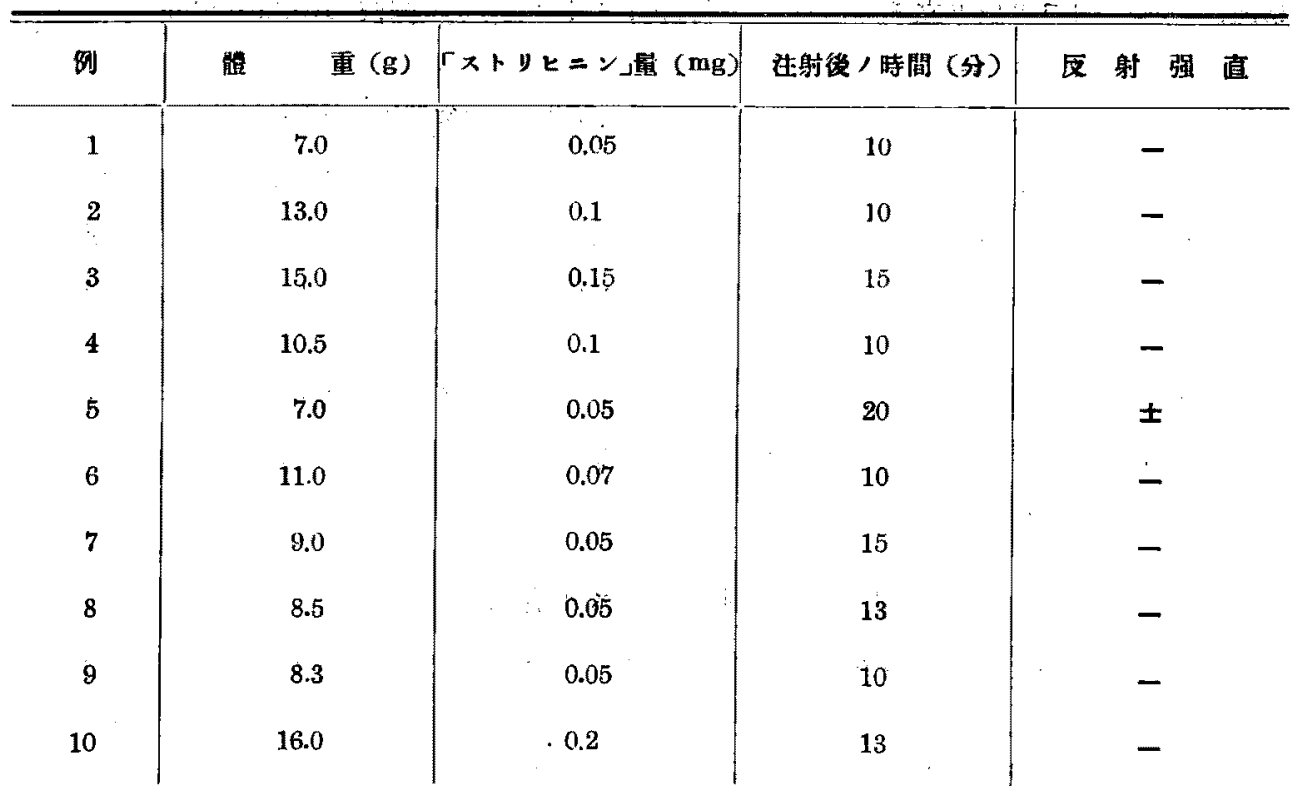

“表中 (一) 八区射强直 （土）ヘ蜼黄ナラザルョ示ス

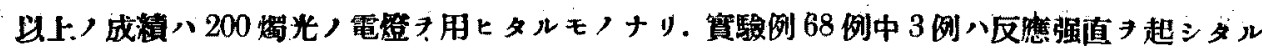

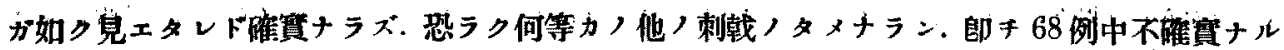

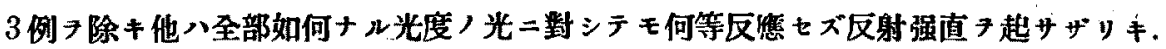

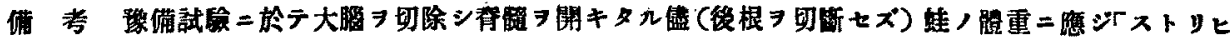

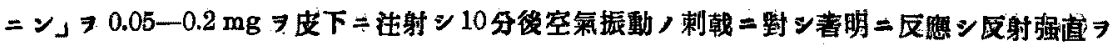
起ス 7 躍メタy. 


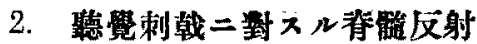

䔈 驗方 法

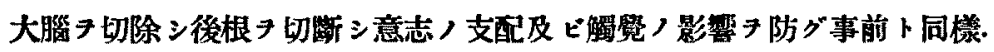

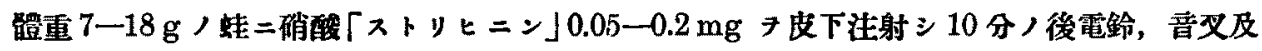

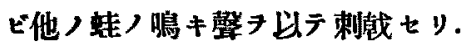

1) 電 鈴 $=ヨ ル$ 刺 载

試驗蛙トノ距離 72 閒以上トセリ.

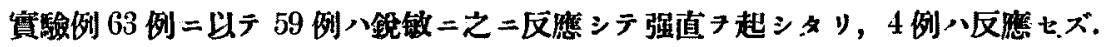

2) 音 叉 $=\exists$ 刺 羢

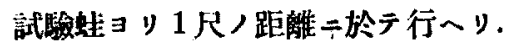

其成續次 $/$ 如シ。

\begin{tabular}{|c|c|c|c|c|c|}
\hline 甽 & 重 $(\mathrm{g})$ & 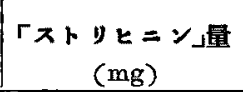 & 注射麸時閣(分) & 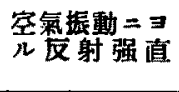 & 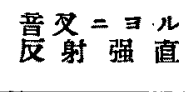 \\
\hline 1 & 13.0 & 0.15 & 10 & - & $H$ \\
\hline 2 & 12.0 & 0.15 & 12 & - & + \\
\hline 3 & 13,3 & 0.15 & 10 & - & $H$ \\
\hline 4 & 9.5 & 0.1 & 13 & - & + \\
\hline 5 & 15.0 & 0.2 & 15 & - & \pm \\
\hline 6 & 7.4 & 0.05 & 10 & - & $H$ \\
\hline 7 & 7.0 & 0.05 & 10 & - & $H$ \\
\hline 8 & 11.0 & 0.1 & 13 & - & $H$ \\
\hline 9 & 10.5 & 0.1 & 10 & - & $H$ \\
\hline 10 & 12.0 & 0.15 & 10 & - & $H$ \\
\hline
\end{tabular}

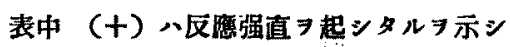

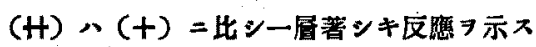

(一) 八反歪セザルヨ示ス

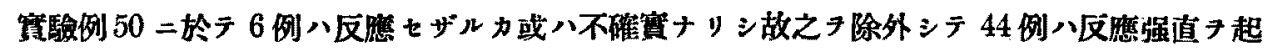

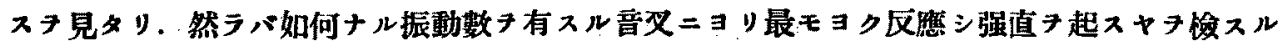

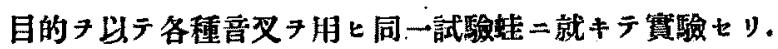

其成續次／如シ. 


\begin{tabular}{|c|c|c|c|c|c|c|c|c|}
\hline $\begin{array}{l}\text { 疍 及, } \\
\text { 種 類 }\end{array}$ & $\begin{array}{r}C_{1} \\
256\end{array}$ & $\begin{array}{l}\mathrm{A} \\
240\end{array}$ & $\begin{array}{l}A_{1} \\
214\end{array}$ & $\begin{array}{c}G \\
192\end{array}$ & $\begin{array}{c}F \\
170\end{array}$ & $\begin{array}{c}\mathbf{E} \\
160\end{array}$ & $\begin{array}{c}D \\
151\end{array}$ & $\begin{array}{c}c \\
128\end{array}$ \\
\hline 安 & & & & & & & & \\
\hline 1 & - & + & + & + & + & + & - & - \\
\hline 2 & - & - & - & + & + & + & + & - \\
\hline 3 & - & - & - & - & + & + & + & - \\
\hline 4 & - & - & \pm & + & + & + & + & - \\
\hline 5 & - & - & - & + & + & + & + & - \\
\hline 6 & - & - & - & - & + & + & + & - \\
\hline 7 & - & - & + & + & + & + & + & - \\
\hline 8 & - & - & - & + & + & + & + & - \\
\hline 9 & - & - & - & - & + & + & + & - \\
\hline 10 & - & - & - & + & + & + & + & - \\
\hline 11 & - & - & - & 土 & + & + & - & - \\
\hline 12 & - & - & - & + & + & + & + & - \\
\hline 13 & - & - & - & + & + & + & + & - \\
\hline
\end{tabular}

即于 15 例ノ㐫 8 例 $八 151-192$

2 例 $160-170,2$ 例 $151-171$

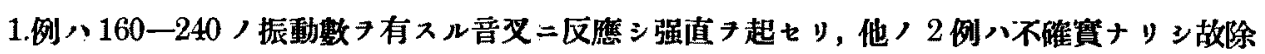
外不.

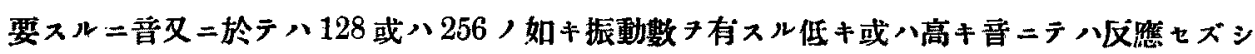

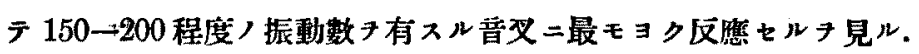

3）他ノ蛙ノ鳴キ警

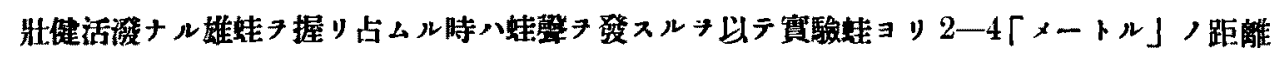

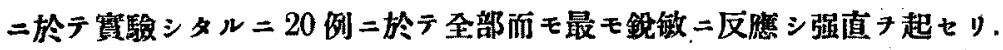

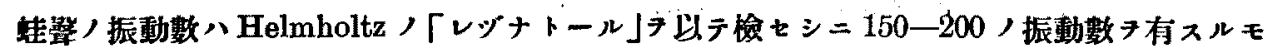
ノナル事フ確カメ得タリ。

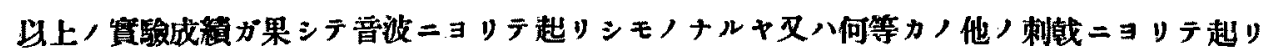

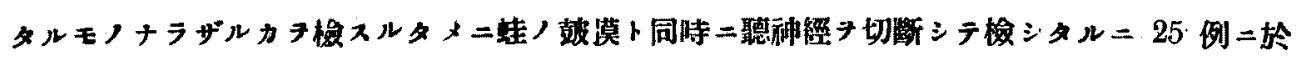
テ只 1 例反㦄浊直テ起シタルノ 全二基クモノナラン. 


\section{結 論}

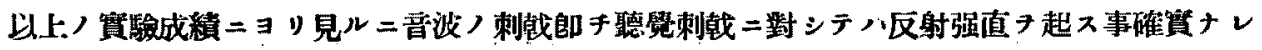

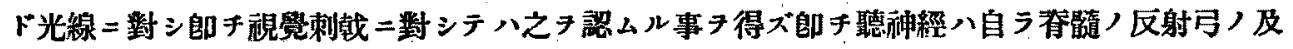
心路尹形成スルモ視神經八自ラ反射弓ノ及心路タナスモノニアラズト推定シ得ハシ. 若シ人體 二於テモ同漛ナリトセバ强キ光例之雷光等二對シテ起ス反射運動ハ單純ナル脊链反射二非ズシ

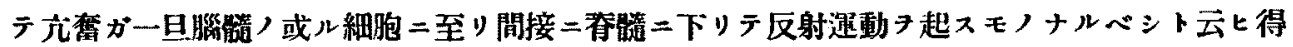
ベシ.

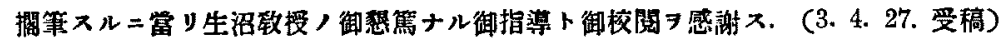

\section{まナル文䰹}

1) Mershıcher, Pfliger Arch. f. d. ges. physiol. Bd. 81, s. 222, 19no. 2) Tangendorff, Du Bois Reymond's Arcl. 1877. 3) Verworn, Zentbl. f. phys. Bd. 23, s. 281, 1909.

4) Verworn, Arch. f. phys. 1900, s. 385 .

5) Tiedemann, Zeitschr. f. allg. phys. Bd. 10, 1910.

6) Bnglioni, Arch. f. phys. 1900. 7) Fröhlich, Zeitschr. f. ullg phys. Bd. 9, $1909 . \quad$ 8) Biedermann. Pflïger Arch. Bd. 80. s. 408, 1900.9 9) Buglioni, Zeitschr. f. allg. phys. Bd. 4, 1904. 10) Zwarrdemakea und Lans, Zentralbl. f. phys. Bd. 13, 1899. (11) Sherrington, Ergebn. d. phys. Juhrg. 4, 1905. 12) Julius Veszi, Zeitschr. f. allg. phys. Bd. 11. s. 168, 1910. 13) Bjeberfeld, PAinger Arch. f. d. ges. phys. Bd. 83. s. 397, 1900. 14) Eckhnrdt, Pflïger Arch. Bd. 83, s. 403, 1900. 15) Schliok, Pflitger Arch. Bd. 47, s. 171, 1880. 16) Wilh. Filibne, Pfiuger Arch. Bd. 88, s. 506, 1902. 17) Eckhard, Beitrige zur Anat. u. phys. Bd. 9. s. 15. 18) Meihuizen, Pflüger Alch. Bd. 7, s. 201. 19) Walton, Arch. f. Anat. u. phys. 1882. s. 46. 20) Geinitz und Winterstein, Pflüger Arch. Bd. 115, s. 273, 1906. 
Krrze Inhaltsangàbe.

\title{
Sind die Reflexkrämpfe des strychinisierten Frosches ebenso wie durch akustische auch durch optische Reize auslösbar?
}

\author{
Von \\ Masanori Okada. \\ Aus dem Physiol. Institut der. Universität au Okayama. \\ (Vorstand: Prof. S. Oinuma.) \\ Eingegangen am 27. April 1928.
}

Es wird allgemein angenommen, dass am strychinisierten Tier die Reflexkrämpfe durch akustische ebenso wie durch optische Reize auslösbar sind. $J_{n}$, man findet sogar einige experimentelle Mitteilungen, die diese Frage bejahen.

Ich untersuchte dieses Problem am strychinisierten Froseh mit grosser Sorgfalt und gelangte zu folgendem Resultat:

1) Bei dem vor mechanischer Erschütterung der Haut geschützten strychinisierten Frosch sind die Reflexkrämpfe durch akustische Reize (Flotentőne als Reize benutzt) leicht auslosbar.

2) Optische Reize (Lichtstrahlen verschiedener Stärke, die plotzlich auf das Auge fallen) rufen niemals Reflexkrämpfe am strychinisierten Frosch hervor.

Aus diesen Tatsachen kann man schliessen, dass die optische Bahn keine direkte Verbindung mit dem Reflexbogen des Rückenmarks hat, obwohl die akustische Bahn eine solche aufweist.

(Autoreferat) 